\title{
INFORMATION ON MALPRACTICE: A REVIEW OF EMPIRICAL RESEARCH ON MAJOR POLICY ISSUES
}

\author{
STEPHEN ZUCKERMAN* \\ CHRISTOPHER F. Koller $†$ \\ RANDALl R. BOVBJERG**
}

\section{INTRODUCTION}

Just as it did in the mid-1970's, the medical malpractice system is currently receiving a great deal of attention. Soaring premiums for some physicians, high awards for some injured patients, and the potentially high costs of defensive medicine have led to a number of proposals to reform the present system. The preceding papers in this journal indicate the level of activity in this area. But what really is known about the medical malpractice system, what it costs, how well it compensates for injuries, its impact on the quality of care, and the likely effects of proposed modifications? This article reviews major empirical studies dealing with medical malpractice that have attempted to answer some or all of such questions.

The topic areas used to organize this review are as follows: (a) tracking premiums, claims, and awards; (b) injuries, claims, and resolutions; (c) objectives of the tort system; (d) legal reforms; and (e) malpractice and the health care system. The article focuses on attributes of the medical malpractice system and its relation to medical care. Studies of the insurance industry are not explicitly addressed unless they focus directly on the medical malpractice system. Thus, information on topics such as the appropriateness of insurance rating categories, accuracy of premium levels, and the effects of competition and regulation have been omitted.

Even a casual follower of malpractice policy debates can see that the amount of published and unpublished information is voluminous; however, very little of that information consists of systematic empirical studies. Indeed, information on malpractice can be organized into five categories, with varying degrees of quantitative content and validity. Table 1 describes how sources range from the most common type, largely anecdotal in content, to the rarest, well-designed empirical studies of developments, behavior, and trends.

Copyright $(1986$ by Law and Contemporary Problems

* Research Associate, Health Policy Center, The Urban Institute, Washington, D.C.

$\dagger$ Research Assistant, Health Policy Center, The Urban Institute, Washington, D.C.

** Senior Research Associate, Health Policy Center, The Urban Institute, Washington, D.C. 
TABLE 1

The INFORMation ICEberg: Levels of QUANTITATIVE Research

Categories of Information

Nature and Comments

1. Analysis

2. Generalizable descriptive research

3. Limited descriptive research

Empirical investigations using sound quantitative methods to explain how and why the medical malpractice system functions as it does; least numerous.

4. Medical-legal writing, opinions, and commentary

Organized presentations of broad-based, reliable data whose general purpose is to describe developments sytematically.

Similar to level 2 but lacks generalizability since it tends to be based on relatively narrow data sources.

Tends to be geared toward development of concepts or arguing particular positions; may use quantitative evidence, but rarely develops it.

5. News reports, anecdotal evidence

Most numerous but tend to dwell on specific cases or problems and, as such, are least likely to contain any generalizable data or concepts.

In fact, available studies and reports form a rough pyramid labeled here as the "information iceberg." This review focuses on the top layers of generalizable description and analysis. Note that "analysis" does not mean abstract, academic, or philosophical discussion; it simply means methodologically sound and generally applicable fact-finding. Selective focus on these studies provides the most relevant and high-quality information; adopting a well-defined focus also makes this undertaking feasible.

Before the early 1970's, virtually no aspect of the medical malpractice system had received much general attention. Most writers dealt with strictly legal or medical issues, not quantitative matters. An anecdotal flavor was common even in relatively scholarly articles that touched on empirical issues. Serious empirical efforts date from 1973 when the Secretary of Health, Education, and Welfare's Commission Report and its Appendix were released. ${ }^{1}$ These studies have been seminal documents for almost all subsequent empirical research. The Commission Report and Appendix constitute an admirable overview; they define terms and set out the main public issues very well. In addition, the information could not have been more timely, because the malpractice insurance "crisis" broke very shortly thereafter. ${ }^{2}$ Even with the addition of these specially commissioned studies, however, an extensive body of empirical knowledge was not available to help guide evaluations of malpractice system developments and the legislative responses to them. Of the twenty-nine separate articles contained in the Appendix to the Commission Report, for example, only four can be viewed as providing generalizable empirical evidence on the malpractice system. Another twelve articles contained

1. U.S. Dep't Health, Educ., \& Welfare, Report of the Secretary's Commission on Medical Malpractice \& Appendix (1973) [hereinafter cited as HEW Report].

2. On the "crisis," see, for example, P. Danzon, Medical Malpractice: Theory, Evidence, and Public Policy 97-114 (1985); S. Law \& S. Polan, Pain and Profit: The Politics of MALPRACTICE $161-94$ (1978). 
data but, due to limitations in sample size, response rates, or sampling frames, are not valid for broad inferences.

Since the mid-1970's, considerably more empirical work has been done, as the following sections of this article illustrate, but major gaps remain. One such gap concerns the relationship between medical malpractice and the quality of medical care. Unfortunately, the paucity of information available made a section on this topic impractical.

In 1975, a careful discussion of quality of care and malpractice noted: "Facts about the operation of the present medical malpractice system are sparse. Those that relate to the quality-of-care issue and are consistent among observers of the malpractice system are even more sparse."3 Less progress has been made since then in illuminating quality issues than in illuminating systems and process issues. Although deterring substandard care is perhaps the central purpose of malpractice law, almost no systematic investigation exists on how malpractice experience affects medical quality or vice versa. ${ }^{4}$ Medical literature of course contains many empirical studies of various aspects of medical quality, but none have been located that consider, for example, how quality actually influences litigation and liability premiums-or vice versa. ${ }^{5}$

This article is an effort to review as many studies relevant to malpractice policy as possible. In addition to standard library searches, telephone interviews with researchers and organizations that address these issues were conducted to ensure completeness. Organizations included the American Medical Association, the American Trial Lawyers Association, the California Medical Association, the Congressional Research Service, the General Accounting Office, the Insurance Information Institute, the Insurance Services Organization, and the St. Paul Fire and Marine Insurance Company.

After relevant studies were located, out of necessity they were screened so as to focus on the best of them. In screening the studies to decide which should be included in this review and how much weight to give them, a number of basic criteria were applied. First, highest priority was given to

3. Brook, Brutoco \& Williams, The Relationship Between Medical Malpractice and Quality of Care, 1975 DUKe L.J. 1197, 1205.

4. Bovbjerg, Medical Malpractice on Trial: Quality of Care Is the Important Standard, LAw \& Contemp. Probs., Spring 1986, at 321, 328-29.

5. Clearly, a bad outcome and some substandard medical malpractice are prerequisites to a valid malpractice claim, but it remains unknown to what extent low medical quality, as opposed to other factors, actually leads to claims. Quantitative theories of how medical malpractice actions might influence quality have been addressed. E.g., R. Posner, Economic ANalysis of Law 157-59 (2d ed. 1977); Schwartz \& Komesar, Doctors, Damages and Deterence, 298 New EnG. J. Med. 1282 (1978). Few data appear to be available. A major hypothesis is that a few "bad apples" cause a very disproportionate share of quality problems and of malpractice claims. E.g., Fine \& Sunshine, Malpractice Reform Through Consumer Acceptance and Consumer Education: Are the New Concepts Marketable?, Law \& Contemp. Probs., Spring 1986, at 213. (The case of Dr. Nork's lengthy series of unnecessary and poorly done surgical operations is often cited. E.g., S. LAW \& S. PoLAN, supra note 2, at 215-45.) A few counts have been publicized of how many providers have multiple suits in a given time period, e.g., Rolph, Some Statistical Evidence on Merit Rating in Medical Malpractice Insurance, 48 J. Risk \& INs. 247 (1981), but no known studies address the reasons for or implications of these findings, controlling for case mix or number of procedures, for instance. 
analysis and reporting of data that were collected in a broad based, representative fashion-levels 1 and 2 in Table 1 . Nonrandom or otherwise less reliable information is sometimes noted, however, especially if it is the only possible source. Second, data featuring a large number of observations were favored, especially if they represented a consistent "time series" across a number of years. Reports whose data sets appear to be extremely small relative to the size of the sample universe were disfavored. Reports done in "clinical" or "case study" style, such as those based on 200 records from one hospital, are seldom included. Third, studies that mainly report on opinions or perceptions are also excluded unless they shed light where no data are available. Finally, published or widely circulated material was favored over proprietary or other information that has not been tested by outside review and criticism. Not every empirical study could be found or noted here; doubtless, some worthy research has not been included in this review.

\section{II}

\section{Tracking Premiums, Claims, and Awards}

The most frequently discussed empirical evidence pertaining to medical malpractice concerns insurance premiums, claims, and awards. The majority of studies and reports have only described what is happening, often in a narrow area, rather than attempting to explain why or how the observed outcomes have developed. It seems clear that the level of analysis has been constrained by the nature of the available data.

\section{A. Primary Data Sources}

The amount of primary data that is regularly updated and publicly accessible is surprisingly limited. Although the level of malpractice insurance premiums is a major source of provider and public concern about malpractice developments, no ongoing data sources track what hospitals and physicians in each specialty and rating area are actually paying for insurance. Prices charged by insurance companies are generally not public knowledge either, and insurance companies in a competitive marketplace tend to treat this information as proprietary. It is possible to get quotes on certain types of policies, but this is not the same as knowing what is being paid. The American Medical Assurance Company (AMACO) - a reinsurer for physician-owned companies-has published some of the most detailed data on premiums and limits of coverage, ${ }^{6}$ but even AMACO's reports do not make clear whether the average premium presented is the average rate available or the price of the average policy purchased. In addition, AMACO only covers physicians insured by physician-owned companies.

6. See, e.g., Special Task Force on Prof. Liab. and Ins., Am. Medical Ass'n, Professional Liabilitry in THE '80s, RePORT 2, at 11 (1984) (originally published as a supplement to AM. MED. News, Nov. 1984) [hereinafter cited as AMA TAsk Force, Report 2]. 
The only available data on paid premiums representative of all physicians are collected through provider surveys. Both the American Medical Association's Socioeconomic Characteristics of Medical Practice and Medical Economics publish data on the typical premium expenses incurred by physicians. ${ }^{7}$ Although these surveys are conducted annually and track reported expenses over time, they do not detail how changes in the type and level of coverage may be affecting physicians' expenses. Because neither of these surveys' information can be reliably disaggregated to the state or local level, studies geared toward specific states have been conducted using their own surveys to collect similar data. ${ }^{8}$ No comparable data collection seems to exist for hospitals.

Aggregate premium data organized from the insurers' perspective is available from Best's Insurance Management Reports. ${ }^{9}$ These reports, published annually, present data on a national and state-by-state basis on total premiums, company expenses, and underwriting losses for medical malpractice as a line of insurance business. Best's Reports serves as a barometer of the financial health of malpractice insurers and can help identify the need for future rate increases. More specifically, disaggregated data must come from insurers themselves. On a proprietary basis, Insurance Services Office (ISO) uses disaggregated data based on company experience to develop rating methods often used by commercial insurers. ${ }^{10}$ Given the growth in provider mutuals, " the ISO's suggested rates played a greater role before 1975 than currently.

Ongoing sources of information on claims and awards are more limited than those on premiums. No public sources are available that track the total number of claims and their characteristics from year to year. Again, some data are available from insurance companies, but they are not routinely disseminated nor necessarily comparable across companies. ${ }^{12}$ Surveys conducted by the American Medical Association (AMA) and the American

7. See, e.g., Socioeconomic Characteristics of Medical Practices (R. Reynolds \& R. Ohsfeldt eds. 1984); Kirchner, Is Your Practice Begging for Money?, MED. Econ., Nov. 12, 1984, at 21439.

8. See, e.g., Fla. Medical Ass'n, Medical Malpractice Policy Guidebook (H. Manne ed. 1985); N.Y. Times, Oct. 13, 1985, at 69, col. 1 (reporting on New York State Medical Society study).

9. See, e.g., Best's Ins. Management Reports, On-Line Report, Release No. 18, General Liability and Medical Malpractice Insurance Marketing-1984 (1985). Surprisingly, even for such a simple datum as premiums paid for coverage, the property/casualty insurance industry did not report malpractice premiums separately from general liability until 1975. INS. INFORMATION Inst., InSurance FaCts: 1985-86 Property/Casualty Fact Book 29 (1985).

10. The ISO provides information for its member carriers on premiums and claims, and is the only country-wide source of information available for different lines of liability coverage. See $P$. DANZON, supra note 2, at 93-95 for a concise discussion of the role played by ISO data.

11. Id.

12. See, e.g., Special Task Force on Professional Liab. and Ins., Am. Medical Ass'n, Professional Liability in the '80s, Report 1 (1984) (originally published as a supplement to Am. MED. News, Oct. 1984) [hereinafter cited as AMA TASK Force, RePort 1]; data on insurance experience supplied by Si. Paul Fire \& Marine Ins. Co. (Jan. 1985), reproduced in Urban Institute, Medical Malpractice: Can the Private Sector Find Relief? (R. Bovbjerg \& C. Havighurst eds., Working Paper 3417-01, Mar. 1985). 
College of Obstetricians and Gynecologists (ACOG), among others, have tracked physicians' self-reported claims experiences. ${ }^{13}$ Unfortunately, these data have been more sporadic than the information provided on premium expenses, and the surveys provide very little information on the claims themselves. On the other hand, they do enable analysis of the relationship between claims and physician characteristics. Hospitals' experiences with malpractice claims have not received even this level of public attention.

The sole ongoing source of data on nationwide jury awards is Jury Verdict Research, which publishes data drawn from reports submitted by affected parties. ${ }^{14}$ There are valid questions regarding the representativeness of the numbers reported through this source. ${ }^{15}$ Of particular importance is the fact that most malpractice awards are not made by a jury, and yet Jury Verdict Research excludes all out-of-court settlements from its reports. In light of the attention that million dollar verdicts receive in the media and the potential for those verdicts to be viewed as representative, not having ongoing data on median awards (both in court and out-of-court) is a major limitation in tracking real changes in the malpractice system.

Some of the best claims and other data have not been collected on a continuing basis. Several national closed claims studies exist that contain extensive information on claims and awards. ${ }^{16}$ Closed claims surveys typically contain information such as the place of incident occurrence, cause of the injury, type of defendant, time to claim, time to settlement, claim disposition, award amount, and defense costs. These data are collected directly from insurance company records and are basically cross-sectional in character. In the case of the National Association of Insurance Commissioners (NAIC) study, ${ }^{17}$ all significant insurers reported on all closed claims over several years. The NAIC "survey" thus virtually constitutes a census, whereas the study by Westat for ACOG, and the ISO/AIA study included a sample of malpractice

13. Am. College of Obstetricians \& Gynecologists, Professional Liability Insurance and Its Effect: Report of a Survey of ACOG's Membership (1985) [hereinafter cited as ACOG 1985 Report]; Am. College of Obstetricians \& Gynecologists, Professional Liability Insurance and Its Effects: Report of a Survey of ACOG's Membership (1983); AMA Center for Health Policy Research, Recent Trends in Physician Liability Claims and Insurance Expenses, Socioeconomic Monitoring Sys. ReP. No. 7, Oct. 1982.

14. See, e.g., Jury Verdict Research, Inc., Injury Valuation Reports, No. 292, Current AWARD TrEnds 18 (1985).

15. For a criticism of selective figure citing, see Localio, Variations on \$962,258: The Misuse of Data on Medical Malpractice, Law, Med. \& Health Care, June 1985, at 126.

16. Am. Ins. Ass'n \& Ins. Servs. Office, All Industry Committee Special Malpractice Review: 1974 Closed Claims Survey (1976) [hereinafter cited at ISO/AIA Survey]; NAT'L Ass'N OF INS. Comm'rs, Malpractice Claims: Final Compilation (M. Sowka ed. 1980) (medical malpractice closed claims 1975-1978) [hereinafter cited as NAIC Study]; Rudov, Myers \& Mirabella, Medical Malpractice Insurance Claims Files Closed in 1970, in HEW REPORT, supra note 1, at app. 1; see also HEALTH Care Fin. Admin., U.S. Dep't Health, Educ., \& Welfare, Medical Malpractice Claims: Synopsis of the HeW/Industry Study of the Medical Malpractice Insurance Claims (J. Cooper ed. 1978) [hereinafter cited as WESTAT STUDY].

17. NAIC STUdy, supra note 16. 
insurers in single years. ${ }^{18}$ There was also some variation in the definition of a claim across the studies.

The NAIC file appears to be the richest of the existing closed claims surveys. First, it is the most recent complete data set, although at this point some of its data are almost a decade old. The age of this data may limit its relevance for current debates if significant structural changes have taken place. Second, by including all claims, it allows analysis of claims experience at the state level. Smaller files do not contain enough data on each state to study all states. Third, the large number of claims also allows for better data on paid claims, a small subset of total claims. Finally, with the NAIC data, it is possible to examine changes in claims frequency over time. This is particularly useful, because many legislative changes were being implemented during the study period. A major closed claims study is now underway by the General Accounting Office (GAO). ${ }^{19}$ The GAO study will be bigger than either the Westat studies or the ISO/AIA study, but will not include all claims as the NAIC did. The GAO study, scheduled to be available in late 1986, should show any changes in claims patterns since 1978.

\section{B. Time Trends}

The reason that medical malpractice has become a policy issue is that claims frequency, award amounts, and premiums have been rising over time. The growth in premiums has been documented through insurance company data as well as physician survey data. ${ }^{20}$ The upward trend in claims through the 1970's is also well established. Using the Westat and NAIC closed claims data, a study by Danzon shows that annual claims against physicians and hospitals increased dramatically early in the decade and then tapered off.21 Physician survey data reported in an AMA report and in a study by Zuckerman shows that claims frequency seemed to accelerate again in the late 1970's and early 1980's. ${ }^{22}$ These trends are substantiated by insurance company sources as well. 23

Because of variation in reporting practices, the precise trends occurring in awards are somewhat less clear. For the years 1975 to 1978 , NAIC reports an average award growth of forty-two percent (net of inflation). ${ }^{24}$ As discussed

18. ISO/AIA Survey, supra note 16; WESTAT Study, supra note 16.

19. An outline of the proposed study design is contained in U.S. Gen. Accounting Office, Objectives, Methodologies, and Uses of Data for a Review of Medical Malpractice Issues (1985).

20. See, e.g., Adams \& Zuckerman, Variation in the Growth of Medical Malpractice Claims, 9 J. HEALTH Pol'y, Pol. \& L. 475 (1984); AMA TASk Force, Report 1, supra note 12; AMA TASk Force, RePORT 2, supra note 6; insurance data from St. Paul Fire \& Marine Ins. Co., supra note 12.

21. P. Danzon, The Frequency and Severity of Medical Malpractice Claims 5 (The Rand Corp., Report No. R-2780-ICJ/HCFA, 1982).

22. AMA Center for Health Policy Research, supra note 13, at 1-3; Zuckerman, Medical Malpractice Claims, Legal Costs, and the Practice of Defensive Medicine, Health Aff., Fall 1984, at $128,129$.

23. See, e.g., Insurance data from St. Paul Fire \& Marine Ins. Co., supra note 12; see also Danzon, The Frequency and Severity of Medical Malpractice Claims: New Evidence, Law \& Contemp. Probs., Spring 1986, at 57, 64-67.

24. See NAIC Study, supra note 16 , at 18. 
above, data from Jury Verdict Research that show dramatic growth in jury awards need to be viewed cautiously. ${ }^{25}$ Some "average paid losses" are presented by AMACO for physician-owned companies. ${ }^{26}$ Despite showing a $250 \%$ increase from 1979 to 1983 , these data may have been distorted by the skewed distribution of awards and the aging of the AMACO companies during this period. Data from the St. Paul Fire and Marine Insurance Company (the St. Paul) show that, for their policies, losses per reported claim (including defense costs) rose by about fifty percent over the period from 1979 to 1983. ${ }^{27}$ Danzon reports on the award trend somewhat differently by showing that severity per paid claim grew at twice the rate of increase in the Consumer Price Index for the years 1975 to $1984 .{ }^{28}$ While the precise amount of award growth is subject to debate, the existence of an upward trend cannot be disputed.

\section{Burden of Premiums}

The growth in premiums has led to several descriptive analyses of the burden these premiums pose for physicians and the health care system in general. A study by Greenspan analyzes the distribution of physician premium increases from 1974 to 1976 , and concludes that for most physicians the increases were financially manageable and that only a small number of specialties in selected states were "bearing a financial burden."29 Adams and Zuckerman analyzed AMA data for 1976 and 1981 and also found increases to be small for most specialties. ${ }^{30}$ Based on its most recent data, Medical Economics concludes that median premiums represent less than three percent of median gross practice income for physicians. ${ }^{31}$ It should be noted that these surveys measure total premiums paid, without controlling for the precise coverage purchased. ${ }^{32}$ While concern about the affordability of malpractice premiums has increased in the past few years, no data suggest that the problem is widespread, even though the burden for certain specialists (for example, obstetricians) and physicians in certain areas or states (such as New York) is well above national averages. Very recent developments have of course not yet been analyzed.

25. See Localio, supra note 15 , at 126-27.

26. AMA TASK Force RePort 1, supra note 12, at 18.

27. Tabulation by the authors based on data from St. Paul Fire \& Marine Ins. Co., supra note 12.

28. Danzon, supra, note 23 , at 75 .

29. Greenspan, A Descriptive Analysis of Medical Malpractice Insurance Premiums: $1974-1977$, HEALTH Care Fin. Rev., Fall 1979, at 65, 70.

30. Adams \& Zuckerman, supra note 20, at 479 .

31. Kirchner, supra note 7, at 235-39.

32. Since the mid-1970's, more and more physicians have purchased "claims-made" coverage, which, unlike the traditional "occurrence" policy, does not cover claims in future years and so carries a lower premium for a given "limit" of liability protection. See Posner, Trends in Medical Malpractice Insurance, 1970-1985, Law \& Contemp. Probs., Spring 1986, at 37, 44-45. Thus, in the aggregate, it is reasonable to conclude that physicians get "less" insurance for their reported spending on coverage-so that the lack of change noted between 1976 and 1981 in percentage of income spent may be misleading. On the other hand, at the same time providers have probably purchased higher limits of coverage, thus, possibly obtaining "more" insurance for the reported premium. 
Premiums seem to be less of a financial burden when compared to total health care spending. In 1970, according to one calculation, malpractice insurance premiums accounted for less than one-half of one percent of health care spending. ${ }^{33}$ Even after the rapid growth in premiums during the mid1970's, malpractice insurance costs seem to be about one percent of total health care spending since $1976 .{ }^{34}$

\section{Insurance}

The American Trial Lawyers Association argues that the present premium burden that many physicians contend is excessive is inflated by the rating and reserving practices of malpractice insurers. ${ }^{35}$ In particular, they maintain that reserves needed for future claims are overstated and that this translates into substantial increases in provider premiums. The problems of rating and reserving are not issues specific to the medical malpractice debate, however, and a detailed review of the insurance literature is beyond the scope of this paper.

Some research has considered the appropriateness of premium increases in the context of the increasing claims frequency and the changing market for insurance. Danzon analyzed the causes of the sharp increases during the mid1970 's in malpractice insurance premiums. ${ }^{36}$ She concludes that premiums rose because of rising claims costs, but that premiums lagged behind costs because of competitive pressures. Investment losses also contributed to the need to rebuild insurers' assets. ${ }^{37}$ A large part of the increases remains unexplained, however. Sumner analyzed hospital malpractice insurance and found that, prior to 1973 , it was becoming an increasingly unprofitable line of insurance. He cites generally inadequate data on this relatively small sector of liability insurance market as a prime reason for the profitability decline. His analysis concludes that the premiums increases of 1975 to 1976 seem justified based on increases in claim frequency and costs and insurers' past inability to keep premiums in line with costs. ${ }^{38}$

\section{III}

\section{Injuries, Claims, and Resolution}

The medical malpractice system can be viewed in three stages: first, an unsatisfactory, possibly negligent medical outcome; second, an insurance claim from a patient (often in consultation with a lawyer) or a report from the

33. Steves, A Proposal to Improve the Cost to Benefit Relationship on the Medical Professional Liability Insurance System, 1975 DUKE L.J. 1305, 1317.

34. Posner, supra, note 32 , chart 2 , at 50.

35. See T. Goddard, The American Medical Association Is Wrong-There Is No Medical Malpractice Insurance Crisis (1985) (unpublished paper for the Public Affairs Department, Association of Trial Lawyers of America).

36. P. Danzon, Why Are Malpractice Premiums So High-or So Low? (The Rand Corp. Report No. R-2623-HCFA, 1980).

37. P. DANZon, supra note 2, at 112 .

38. M. Sumner, The Dollars and Sense of Hospital Malpractice Insurance 17-34 (1979) 
insured provider; and finally, claims resolution. This section addresses, in turn, the current state of knowledge about each of these three stages.

\section{A. Medical Injuries and Negligence}

Two basic elements are at the center of the present tort litigation system for medical malpractice: medical injuries and faults. Injuries are patient disabilities that occur as a result of health care management; they are a subset of disappointing or unsatisfactory medical outcomes. Faults (or mistakes) are cases of improper health care management, which may or may not result in an injury. Those injuries that can be proven to be caused by a provider's fault can be viewed as probable plaintiff recoveries. ${ }^{39}$

In contrast to the numerous studies of malpractice claims, there has been only one significant study of negligent injuries from the standpoint of medical practice. The California Medical Association and California Hospital Association (CMA/CHA) commissioned a study of medical injuries resulting from health care management (iatrogenic injuries) in hospitals as part of their Medical Insurance Feasibility Study to determine what level of claims might result under a "no fault" reform.40 A total of 20,864 inpatient charts from twenty-three California hospitals for 1974 were examined by a team of medical/legal experts in order to identify injuries. These injuries, negligent or otherwise, were termed "potentially compensable events" (PCE's). The study found that $4.65 \%$ of all hospital inpatient stays (970 cases) resulted in a PCE. Of these 970 cases, the study estimated that in seventeen percent evidence of fault was present. Therefore, according to this study, about one in twenty hospital inpatients suffers an injury and one in 125 has a legal claim of malpractice. ${ }^{41}$

The CMA/CHA study is uniquely revealing about the extent of hospital injuries and negligence therein, but it is not without its limitations. First, it covers only injuries in hospitals. The NAIC closed claims study shows that seventy-eight percent of paid claims in the mid-1970's resulted from injuries in hospitals, suggesting that many PCE's and negligent injuries must have

39. For a diagrammatic presentation, see Bovbjerg \& Havighurst, Medical Malpractice: A Report for Noncombattants, Bus. \& Health, Sept. 1985, at 38, 40. They draw on work by Don Harper Mills. See infra note 41.

40. See Cal. Medical Ass'n and Cal. Hosp. Ass'n, Medical Insurance Feasibility Study (D. Mills ed. 1977); see also infra note 41.

41. The results of this study are summarized in Mills, Medical Insurance Feasibility Study-A Technical Summary, 128 W.J. of MED. 360 (1978). For a pilot study of this area, see Pocincki, Dogger \& Schwartz, The Incidence of Iatrogenic Injuries, in HEW REPORT, supra note 1, app. at 50. This analysis was based on an extremely limited set of data. Only 800 medical records from two urban hospitals were reviewed by two medical-legal experts. They found a higher rate of injury (7.6\%) and a higher rate of negligence among these injuries $(29.0 \%)$ than the CMA/CHA researchers. The two hospitals were considered somewhat representative of the mainstream of American institutional health care, id. at app. 51, and the records in the sample were "reasonably representative" of the total discharges in each hospital. However, the low sample size in light of the frequency of injury (only 62 injuries were detected) makes it difficult to draw conclusions from this study. At best, this study could be viewed as a pilot study for some of the methods used in the California analyses. 
been missed by the CMA/CHA investigators. ${ }^{42}$ Second, the study explored medical records from only a single state. There is no way of knowing whether California is typical of the rest of the country with respect to injuries. Finally, the study provides no evidence on trends over time, and may now itself be somewhat out of date. These remarks illustrate common deficiencies in the literature, and are not meant to deride the California analysis. Trend analysis would make it possible to determine if the increase in claims frequency in the decade after this study was related to an increase in the incidence of injuries, which would suggest a possible reduction in quality of care, or due to other factors, such as a general increase in society's litigiousness. Many studies of medical outcomes do, of course, exist, but the CMA/CHA study is the only one that relates medical judgments of quality to malpractice standards. ${ }^{43}$

\section{B. From Injuries to Claims}

Why do claims arise in some circumstances and not in others? Relatively little is known about how claims develop after a medical injury occurs. More is known about variation in claims frequency at an aggregate level. Claims can be aggregated across patients and bad medical outcomes, by the type of physician (or practice), and by geographic area. When aggregated, claims are reported, for example, as annual numbers of claims per 100 physicians or claims per 100,000 population. Information on the characteristics of events after a claim is filed (as opposed to potential claims) is more complete as a result of the compilation of closed claims data.

Since the only study of medical injuries and negligence is the CMA/CHA project, it is not surprising that the primary investigation of the relationship between injuries and claims relies on the California results. Danzon analyzed NAIC closed claims data for California hospitals from the same period as the injuries observed in the CMA/CHA study, comparing the number of actual claims to the estimated numbers of injuries. ${ }^{44}$ She estimated that, on average, only one malpractice claim was filed for every ten potentially valid claims and that only four paid claims resulted from every 100 injuries. ${ }^{45}$ The rate of claims tended to be higher for permanent disabilities than for temporary ones. However, even for major, permanent, partially negligent injuries (the group with the highest probability of bringing a suit), only about one claim seemed to result from six injuries as estimated by CMA/CHA. ${ }^{46}$ Danzon also concluded that younger patients file proportionately more claims, since the expected value of recovery decreases with age. ${ }^{47}$

42. NAIC STUDY, supra note 16 , at 20.

43. See, e.g., Steel, Gertman, Crescenzi \& Anderson, Iatrogenic Illness on a General Medical Service at a University Hospital, 304 NEw ENG. J. MED. 638 (1981). The relationships between quality and malpractice have been insufficiently investigated to be included in this review. See supra text accompanying note 5 .

44. P. DANZON, supra note 2 , at 20-25.

45. Id. at 24 .

46. Id.

47. Id. Danzon noted that while one claim in ten negligent injuries is an upper bound because incidence data cover only hospital injuries while the claims figures are for all medical services, a 
Danzon's analysis is not based on primary data about a set of injured patients, some of whom bring claims and some of whom opt not to bring claims. Unfortunately, primary data of this type are not available and, given the low probability of an injury occurring, may be too costly ever to collect. In light of these gaps in the data, studies of claims incidence have focused on more aggregated units of analysis than the injured patient (for example, claims per 100 insured doctors).

The majority of studies have analyzed claims incidence without having explicit data on patient injuries. These studies can be divided into two groups: those based on state-level claims data and those based on providerlevel data. ${ }^{48}$ The earlier state-level study was by Feldman and used data on claims per 1000 persons in 1970. He found that states with a higher frequency of surgery, higher per capita income, and lower lawyer earnings had higher rates of malpractice claims. ${ }^{49}$ Danzon, using NAIC closed claims data from 1975 to 1978 aggregated to the state level, could not confirm Feldman's results with respect to the relationship of surgery to claims. ${ }^{50}$ In addition, she found claims rates higher in states that were more urbanized and had more physicians per capita than other states. ${ }^{51}$ She was unable to uncover any relationship between claims frequency and the number of lawyers or the age of the population in the state, controlling for other factors, including urbanization. ${ }^{52}$

The provider-level studies generally explored the characteristics of the individual provider as opposed to the state's environment. Langwell and Werner show that the probability of incurring a claim is highest for surgeons. ${ }^{53}$ They also found that men are more likely to be sued than women,

steady injury incidence rate and increasing frequency rate will probably raise this upper bound for more recent years. Id. at 24-25. Danzon also was forced to adjust claims and incidence data to account for size differences and the lag between incidence, filing, and closure. Id.

48. This review has followed the majority of the literature by considering claims frequency and award size separately. However, Sloan analyzes variation in the malpractice system through a more bottom line indicator, physician liability insurance premiums. Sloan, State Responses to the Medical Malpractice Insurance "Crisis" of the 1970s: An Empirical Assessment, 9 J. Health Pol'y, Pol. \& L. 629, $638(1985)$.

49. Feldman, The Determinants of Medical Malpractice Incidents: Theory of Contingency Fees and Empirical Evidence, 7 ATL. Econ. J. 62 (1979). Reder, in An Economic Analysis of Medical Malpractice, 5 J. LEGAL STUd. 267 (1976), undertook an earlier claims analysis that presented both a theoretical and empirical model of medical malpractice. His empirical results were seriously constrained by the data to which he had access. He suggests that his key analysis variable should have been "number of claims per unit of medical service." Id. at 279. However, he was forced to use a proxy for malpractice risk equal to the cost of malpractice insurance. $I d$. His independent variables were the annual number of surgical operations per surgeon, per capita income, attorneys per capita, and an index of the legal environment, $i d$. at 218 , based on Dietz, Baird, and Berul's analysis in the appendix to the HEW Report. See Dietz, Baird \& Berul, The Medical Malpractice Legal System, in HEW REPORT, supra note 1 , at app. 87, 128-40. While generalizations from the empirical results of the Reder study were difficult, this work formulated both theoretical and empirical structure that later analysis built upon.

50. P. Danzon, supra note 21, at 25; see also P. Danzon, supra note 2, at 72.

51. P. Danzon, supra note 21 , at 26.

52. Id. at 27.

53. Langwell \& Werner, Regional Variations in the Determinants of Professional Liability Claims, $5 \mathrm{~J}$. Health Pol'y, Pol. \& L. 498, 510-11 (1980). 
group physicians more likely than solo practitioners, and older physicians more likely than younger physicians. ${ }^{54}$ Being a foreign medical school graduate does not affect the probability of being sued.55 In another physician-based study, Adams and Zuckerman show that physicians who spend more time with their patients, particularly among medical specialists and obstetricians and gynecologists, incur fewer claims. ${ }^{56}$

Analysis based on both types of data have examined the impact of a state's legal system on claims frequency. For the most part, hypotheses consistent with the legal parameters identified by Dietz, Baird, and Berul have been tested. ${ }^{57}$ Feldman found that states with a broad discovery rule that extends the statute of limitations and states that do not grant governmental immunity to public providers have higher claims frequency. ${ }^{58}$ Based on both the study by Danzon and the study by Adams and Zuckerman, it also appears that court systems that require defendants to meet high standards of informed consent encourage more claims. ${ }^{59}$ An interesting aspect of these analyses is that several of the legal doctrines discussed by Dietz, Baird, and Berul did not have a strongly independent effect on claims frequency. ${ }^{60}$ These doctrines included an expanded locality rule, res ipsa loquitur, and respondent superior.

\section{Claims Resolution}

Claims resolution, as opposed to claims initiation, is an area about which considerably better descriptive information exists. Final resolution may involve payment of the claim, or dropping the claim without payment, and can occur at any stage of the judicial process from prelitigation to postverdict, either by settlement or by court judgment. The detailed closed claims studies in the 1970's provide descriptive data on the entire resolution process. Such data describe such factors as the number of claims resolved at each stage of the process, what proportion were paid, and the length of time to resolution. In 1974, about fifty percent of the resolved claims emanated from injuries that were over two years old. These claims accounted for eighty-seven percent of the total amount paid in claims in this period. ${ }^{61}$ Moreover, a later study by

54. Id.

55. Id.

56. Adams \& Zuckerman, supra note 20 , at 485. Results for surgical and other specialists were not statistically significant at a $10 \%$ confidence level. Results for medical specialists were significant at that level. Results for obstetricians and gynecologists were significant at a one percent confidence level.

57. See Dietz, Baird \& Berul, supra note 49, at app. 128-40, for a description of those parameters.

58. Feldman, supra note 49 , at 62.

59. P. Danzon, supra note 21, at 28; Adams \& Zuckerman, supra note 20, at 485.

60. Conclusive evidence on specific legal doctrines is only possible when the doctrines are analyzed individually. When a number of doctrines are described jointly in a single variable, and this variable has a significant effect on claims, it is not possible to draw inferences about the component doctrines. Adams and Zuckerman, and Sloan do not aggregate individual doctrines. See Adams \& Zuckerman, supra note 20; Sloan, supra note 48. Feldman and Danzon present both aggregated and disaggregated variables. P. DANzon, supra note 21 ; Feldman, supra note 49.

61. ISO/AIA Survey, supra note 16, at 17-18. 
the NAIC showed that resolution time was increasing through the 1970's for all types of claims. ${ }^{62}$

The NAIC study detected a growing dependence on courts to dispose of claims. From 1975 to 1978 the percentage of claims resolved by litigation grew from seven to eighteen percent. ${ }^{63}$ Claims against physicians were more likely to go to court than claims against hospitals. ${ }^{64}$ In 1975 , plaintiffs were successful in about twenty percent of the cases resolved by court action, but by 1978 this figure fell to approximately ten percent. ${ }^{65}$

Analysis of closed claims by Danzon shows that awards are strongly related to the severity of the injury. ${ }^{66}$ She also found that economic factors play a role. If defense costs are higher, awards tend to be high, but if plaintiff costs are high, awards tend to be lowered. ${ }^{67}$ Danzon concludes that the single most important factor influencing plaintiff victory is whether or not the insurer views the case as one with legal merit. ${ }^{68}$ Other factors determining plaintiff success were the size of the expected award and the legal costs of the involved parties. She also found that claims with higher expected awards, low litigation costs, and a high degree of uncertainty are more likely to end up being decided by a court. 69

Danzon and Lillard extended the above study and drew a number of policy implications regarding the resolution process. States that imposed caps on contingent fees of plaintiffs' attorneys increased the rate at which claims were dropped and, consequently, reduced the number of cases going to court. ${ }^{70}$ Contingent fee limits reduced the average settlement as well. ${ }^{71}$ (See also the discussion of tort reforms in the next section.) Danzon and Lillard also estimated the effects of a reduction in plaintiff and defendant litigation costs. Decreasing the defendant's costs by thirty percent would reduce average preverdict settlements by one-fifth, while reducing only the plaintiff's costs by this percent would slightly decrease both average settlements and the number of cases dropped, and increase by over a fifth the number of cases taken to verdict. ${ }^{72}$

62. NAIC STudy, supra note 16 , at 21 .

63. Id.

64. Id.

65. Id.

66. P. Danzon, The Disposition of Medical Malpractice Claims 30 (The Rand Corp., Report No. R-2622-HCFA, 1980).

67. $I d$. at $36-37$.

68. Id. at 49 .

69. Id. at $\mathbf{5 4}$.

70. P. Danzon \& L. Lillard, The Resolution of Medical Malpractice Claims: Research Results and Policy Implications 18-19 (The Rand Corp., Report No. LR-2793-ICJ, 1982).

71. Id. at 20-21. See also discussion of tort reforms at notes 91-103 infra.

72. Id. at 27-29. 
IV

\section{Objectives of the Tort System}

In theory, the malpractice tort system has two main goals: to compensate the victims of negligent behavior and to deter doctors and hospitals from substandard medical practice. Analyses relevant to the compensation goal are available to a far greater degree than are analyses of deterrence. As has already been noted, deterrence and quality of care are not being addressed in this review.

In order to discuss the available evidence on tort law and insurance as a system of compensation, several questions should be addressed. First, what proportion of injured patients recover anything through the current process? Second, are jury awards or settlements rational and fair to the parties involved? Third, are the costs of operating the present system appropriate or is too much diverted from compensation to administration? Finally, does the system get money to injured patients in a reasonable amount of time?

Danzon's follow-up analysis to the CMA/CHA study of negligent injuries shows that fewer than four percent of hospital patients injured due to negligence received any compensation. ${ }^{73} \mathrm{~A}$ comparison of those compensated with all injured patients shows that only one out of 150 injured hospital patients was paid any damages (based on mid-1970's data). ${ }^{74}$ Here again, the limited evidence on injuries has restricted further analysis of this first aspect of compensation. Since the rate of claim-filings has roughly doubled since the mid-1970's, the rate of compensation also may have increased.

The rationality of payment amounts is better understood. Studies by Danzon and by Danzon and Lillard clearly suggest that severity of injury is an important determinant of the size of the award. ${ }^{75}$ It has been shown that the relationship between severity and award amount is a major reason explaining why indemnity dollars are so unevenly distributed. ${ }^{76}$ Danzon and Lillard conclude that compensation is distributed fairly since the "distribution [of dollars is] in direct relation to the severity of the injury, and hence, the extent of the economic loss."77

This conclusion does not mean that compensation is necessarily "fair" relative to economic loss. That is, people may be over- or undercompensated by the system. Three closed claims studies have attempted to look at compensation relative to economic losses. Their results offer no consensus on the effectiveness of the system. ISO/AIA found that claims with lower economic losses tended to be overcompensated, while those with higher

73. P. Danzon, supra note 36 , at 23.

74. This is the authors' analysis of figures found in P. DANzon, supra note 36, at 20-25, and in Mills, supra note 41 .

75. P. Danzon, supra note 66, at 30; P. Danzon \& L. Lillard, supra note 70, at 16.

76. P. DANzon \& L. LiLLARD, supra note 70, at 23.

77. Id. at 31 . 
losses were undercompensated. ${ }^{78}$ NAIC estimated the average award amounted to $174 \%$ of estimated economic loss. ${ }^{79}$ Westat found that awards undercompensate for economic losses at all levels. ${ }^{80}$ There is some evidence to suggest that malpractice jury awards are higher than awards for similar injuries in some types of cases. ${ }^{81}$ One author concludes that, together with workplace injury and product liability cases, "malpractice ... cases still received awards so high that they cannot be entirely explained by severe injury and high economic loss." 82 Danzon argues that some of this variation may be due to the extent of different defendants' insurance coverage; physicians and corporate defendants are better insured than most others. ${ }^{83}$

A range of estimates exists about the costs of operating the tort liability system for malpractice compared with amounts actually paid to injured patients. The lowest estimate is that plaintiffs receive only eighteen percent of malpractice insurance premiums. ${ }^{84}$ An "unofficial estimate" by the Medical Liability Mutual Insurance Company of New York put the figure at fifty-four percent of premiums. ${ }^{85}$ After reviewing several studies, a New York state panel concluded that twenty-five to forty percent of premiums seemed to be a reasonable upper boundary. ${ }^{86}$ Danzon, assuming that one-third of the gross award is paid for attorney fees, estimated that plaintiffs receive about forty to fifty percent of premium dollars. ${ }^{87}$ Not all estimates specify their assumptions about attorney fees and other factors. Based on any of these estimates, malpractice insurance clearly returns less of its premium dollars in the form of benefit payments than either workers' compensation (paying fifty-five to seventy percent) or first-pay health insurance (eighty-five to ninety percent). ${ }^{88}$

The issue of whether or not the length of time to resolution is reasonable has never been addressed. All that is known about disposition time comes from closed claims data. For example, from 1975 to 1978, the length of time required to settle a claim rose from thirty-seven months from the time of injury to forty-six months. ${ }^{89}$ Claims that settle for higher payments take

78. ISO/AIA Survey, supra note 16, at 26-27.

79. Authors' analysis of NAIC figures summarized in WESTAT STUdy, supra note 16, at 73.

80. Id.

81. See, e.g., M. Peterson, Compensation of Injuries: Civil Jury Verdicts in Cook County 36 (The Institute for Civil Justice, The Rand Corp., Report No. R-3011-ICJ, 1984); M. Shanley \& M. Peterson, Comparative Justice: Civil Jury Verdicts in San Francisco and Cook Counties 19591980, at 50-83 (The Rand Corp., Report No. R-3006-ICJ, 1983).

82. M. Peterson, supra note 81 , at 35 .

83. P. Danzon, supra note 2, at 56.

84. Johnson \& Higgins of S. Cal., Patient's Compensation: An Alternative to the Medical Malpractice System 3 (1975).

85. Special Advisory Panel on Medical Malpractice, State of New York, Report 250 (1976).

86. Id. at 249.

87. See P. Munch, The Costs and Beneftrs of the Tort System If Viewed as a Compensation System (The Rand Corp., Report No. P-5921, 1977) (author is Patricia Munch Danzon). 254.

88. Special Advisory Panel on Medical Malpractice: State of New York, supra note 85, at

89. NAIC STUDY, supra note 16 , at 21. 
longer to dispose.90 Systematic comparisons of these disposition times with those of other types of litigation were not found in the literature.

$\mathrm{V}$

\section{Legal Reforms of the Tort System}

\section{A. Post "Crisis" Reforms}

Virtually all state legislatures responded to the malpractice crisis of the mid-1970's by implementing a series of reforms aimed at reducing the number and dollar amount of malpractice awards, based upon the theory that providing insurers with greater certainty in predicting future claims would encourage them to continue to offer coverage to providers. Tort modifications to reduce awards, to reduce the number of litigants, to provide alternatives to jury trials, and to change insurance laws were all proposed and implemented. ${ }^{91}$

Not all states adopted the same types of reforms. Danzon studied the determinants of the post-1975 reforms in an effort to explain variation in the legislative actions of the states. Using regression models, she found that the absolute number of reform laws passed by a state was significantly and positively related to its degree of urbanization and pro-plaintiff trends in its common law. There was an inverse relationship between the market share held by the largest malpractice insurer and the number of reform measures passed. ${ }^{92}$ By contrast, some factors included in the study which conventional wisdom might have indicated would have a strong effect on the extent of the reforms-percentage increase in malpractice premiums in 1975, number of lawyers and physicians per capita, and relative strength of a state's medical society-all had insignificant effects. ${ }^{93}$

What effect have the legal reforms had on the malpractice system? Through 1985, three studies looked at this issue. ${ }^{94}$ Each used time series data to provide a "before and after" analysis of the reforms, and each suffers from two basic problems. First, the legal reforms that were implemented were diverse and detailed and, therefore, difficult to summarize in a small number of quantifiable measures. As such, the legal reforms were likely to be measured with some error in all cases. The second basic problem relates to the time frame of the data. None of the data on potential outcomes of reforms extends beyond 1978; therefore, the results must be interpreted as the effects of the reforms in the shortrun and may be either underestimating or overestimating reform effects. The only study to assess longer-run data on the effects of tort reforms appears in this volume. ${ }^{95}$ It analyzes claims frequency and severity over ten years (through 1984) based on the experience

90. Westat StUdy, supra note 16 , at 14 .

91. See Sloan, supra note 48 , at $633-37$ for a discussion of these tort reforms.

92. P. Danzon, supra note 21 , at 35 .

93. Id. at 33-35.

94. P. Danzon, supra note 21 ; P. Danzon \& L. Lillard, supra note 70; Sloan, supra note 48.

95. Danzon, supra note 23, at 71-72, 76-78. 
of a subset of malpractice insurers and finds results "broadly consistent with economic theory and with previous evidence." 96 Since the article was being written at the same time as this review, its results are only highlighted here, and interested readers are urged to refer directly to it.

Danzon and Lillard considered the effect of reforms on events after a claim was filed. In their model, using claims closed in 1974 and 1976, they determined that the general effects of reforms passed in the interim were to reduce settlement size, verdict size, and the number of cases taken to court. Specifically, caps on awards, removing ad damnum clauses, and structuring awards worked as intended. Modifying collateral source rules to admit evidence on compensation from other sources had a weaker effect. ${ }^{97}$

Danzon analyzed the reforms' effects on claim frequency and award size using a larger data base that included Westat (for 1970) and NAIC (for 197578) data. She has extended this study with data through 1984 in her article in this symposium. Her findings are generally consistent with the earlier Danzon and Lillard study with respect to award size; however, she did find that mandatory collateral source offsets reduced awards considerably. Based on her most recent estimates, it appears that these offsets reduce awards by about eighteen percent. ${ }^{98}$ There also was no discernible difference between mandatory and evidentiary collateral source offsets. Both classes of offsets lowered the frequency of claims by approximately fourteen percent. ${ }^{99}$ Danzon concludes that this reduction may be the result of fewer small claims being filed due to their lower potential monetary rewards. ${ }^{100}$ While Danzon had earlier found that legislated decreases in the statute of limitations had little effect through 1978, her later analysis estimates that for each year the statute of limitations is cut, claims frequency falls by eight percent. ${ }^{101}$ It appears that the earlier data were from a period too soon after the legislation to detect any changes resulting from the reduced statute of limitations.

Sloan, in a somewhat more "bottom line" approach, concludes that legal reforms were ineffective. ${ }^{102} \mathrm{He}$ argues that the final objective of legislative malpractice reform is lowering the physician premium levels-which in an open market reflects claims frequency and severity, as well as all other relevant factors, such as propensity to sue or changes in probabilities of adverse outcomes. Statewide average premiums from 1974 to 1978 and their annual percentage change were examined as a function of several control variables (income, surgical operations, lawyers, and physicians per capita) and fourteen different legal reforms, expressed in pro-defendant form. For the years 1974 to 1977, Sloan found no significant effects among any of the

\footnotetext{
96. Id. at 78 .

97. P. Danzon \& L. Lillakd, supra note 70 , at 25-27.

98. Danzon, supra note 23, at 77.

99. Id. at 72 .

100. Id. at 78 .

101. Id. at 71-72.

102. Sloan, supra note 48 , at 643 .
} 
variables in reducing physician premiums; most, in fact, were slightly positively related. ${ }^{103}$

\section{An Existing Alternative: Arbitration}

Promoting arbitration of medical malpractice disputes has frequently been suggested as a reform alternative to conventional insurance claims settlement and litigation. ${ }^{104}$ Many states have passed legislation designed to encourage arbitration. ${ }^{105}$ Proponents assert that arbitration systems are speedier and less costly than traditional legal processes, that they encourage small but meritorious claims, and that they are equally fair to injured claimants and defendants alike. ${ }^{106}$ Skeptics assert that the process lacks procedural safeguards, underpays claimants, and is not cost-effective as a response to malpractice premium increases because arbitration encourages higher rates of claims, and is not substantially less expensive than litigation of similar claims. ${ }^{107}$

Available empirical studies cannot resolve these issues. Much reported experience to date may be atypical because arbitration is new to almost all medical providers and because the validity of the state statutes under which it is conducted was established very slowly. ${ }^{108}$ Moreover, as will be discussed below, controlled comparisons with conventional litigation are difficult to conduct.

With regard to the frequency of claims, only one study was found that matched the experience of comparable medical services. This 1976 study found that eight hospitals offering arbitration had eleven percent fewer claims during five years of arbitration than did eight others in a comparison group, despite having had the same number in the years before arbitration. The difference in the rate of claims seemed to be increasing over time. ${ }^{109}$ Less systematic reports indicate that claims frequency has continued to increase

103. Id. at 639-42. Sloan also concluded that whatever premium reducing effect a reform might have would occur relatively soon after its implementation.

104. E.g., Ginsburg, Kahn, Thornhill \& Gambardella, Contractual Revisions to Medical Malpractice Liability, Law \& Contemp. Probs., Spring 1986, at 253, 257.

105. See, e.g., Bedikian, Medical Malpractice Arbitration Act: Michigan's Experience with Arbitration, 10 AM. J. L. \& MED. 287, 287, 305-06 (1984) (Michigan's model as "an archetype"); Ladimer, Solomon \& Mulvihill, Experience in Medical Malpractice Arbitration, 2 J. Legal MED. 433, 465-67 (1981) (chart of statutory provisions for binding arbitration in thirteen states and Puerto Rico in 1981).

106. E.g., Ladimer, The Case for Medical Malpractice Arbitration, 1979 NAT'L MediCAL-Legal Symp. 22 (Am. Medical Ass'n and Am. Bar Ass'n proceedings Mar. 8-11, 1979).

107. E.g., Bedikian, supra note 105 , at $288 \&$ n.4.

108. Michigan's 1975 statute provoked extensive litigation, for example, culminating in the state supreme court ruling in Morris v. Metriyakool, 418 Mich. 423, 344 N.W.2d 736 (1984). See Bedikian, supra note 105, at 293-303. Detroit area filings for arbitration rose steadily at first, then declined, coincidental with the constitutional challenges, whereas litigated cases continued to grow. APPLIED Social Research, Inc., Evaluation, State of Michigan Medical Malpractice Arbitration Program, Summary Report 283 (1983).

109. D. Heintz, An Analysis of the Southern California Arbitration Project, January 1966 THROUGH JUNE 1975, at 14-15 (1975) (420 claims versus 473, compared with 232 and 228 before arbitration). 
after the introduction of arbitration, but surmise that the increase results from the general upward trend in malpractice claims, not from arbitration itself. 110

With regard to resolution of claims once filed, many attributes of arbitration are of interest, especially in comparison with comparable litigated cases-for example, speed of settlement, proportion closed with payment, patterns of payment, level of administrative and legal costs, and consistency and fairness of compensation. A number of sources provide some relevant information, but none is definitive. Most accounts report aspects of a single arbitration program's experience. ${ }^{11}$ The broadest source is the data system of the American Arbitration Association (AAA). The AAA seeks to include all known closed arbitration cases from all programs and jurisdictions, but it included only 205 cases from the 1970's, three-quarters of which were from California and Michigan. ${ }^{112}$ Another data source is the NAIC closed-claims study of 1975-1978, which contains 239 claims closed by binding arbitration. ${ }^{113}$ Clearly, a major problem in assessing the attributes of arbitration is that so few cases have been arbitrated. ${ }^{114}$ Small study universes and selection bias hinder any comparative evaluation of arbitration-no perfect natural "comparison group" exists, and the number of cases is too small to allow for good statistical control through multivariate regression analysis. Moreover, only California and Michigan have significant experience with arbitration, so results may be geographically biased. The studies themselves often emphasize the dangers of overgeneralizing from their limited results. ${ }^{115}$

Four comparative analyses deserve mention. The first broad-based study of arbitration versus litigation was Heintz's examination of claims at sixteen southern California hospitals from 1969 to $1975 .{ }^{116}$ The number of closed

110. E.g., Letter from Kaiser Foundation Health Plan, Inc., to New York State Insurance Department 3 (Sept. 23, 1985) (experience in two of the five Kaiser HMO's that use arbitration). But see supra note 108 .

111. E.g., Rubsamen, The Experience of Binding Arbitration in the Ross-Loos Medical Group, in HEW REPORT, supra note 1, at app. 424; letter from Kaiser Foundation, supra note 110.

112. Ladimer, Solomon \& Mulvihill, supra note 105, at 444-47 (covering 1967-1979).

113. The NAIC compilation of closed malpractice claims covers virtually all cases nationwide during 1975-1978. See NAIC STUDY, supra note 16, at 4. Danzon reports on cases closed by arbitration in P. DANzon, supra note 2, at 203.

114. Medical arbitration began in California in 1929 with the Ross-Loos Medical Group's program, and cases from that state dominate experience. Nonetheless, the AAA had 126 closed arbitration claims from Southern California during 1971-1980, versus 3204 litigated claims from only a three and a half year period in 1975-78. Ladimer, Solomon \& Mulvihill, supra note 105, at 447, 462. The California Medical Association publishes occasional "snapshots" of use of arbitration in that state, long the location of most medical arbitration. The focus has been on extent of use and reasons therefor, not on attributes of the process or results. It appears that after peaking in 1980 , use of arbitration has declined; the authors surmise that arbitration's costs are higher than desired and benefits lower (to the providers), but lack data to evaluate experience. Gyorgy \& Jones, Arbilration in Medical Professional Liability, Socioeconomic ReP., Jan./Feb. 1985, at 1; Jones, L'se of Arbitration in Medical Office Practices, 20 Socioeconomic ReP., July/Aug. 1980.

115. Ladimer, Solomon \& Mulvihill, supra note 105, at 447 ("generalizations should not be made"); Applied Social Research, InC., supra note 108, at 6-7.

116. D. HeinTz, supra note 109. Highlights of his findings included indications that: there was no difference between arbitration and litigation in speed of claim filing; arbitration was three months faster than litigation from filing to resolution; there was little difference between the two in 
claims examined, however, was quite small, and only four cases were arbitrated to a final panel decision during the five and one-half years of arbitration. Moreover, the study could not effectively control for the selfselected nature of arbitrated claims; arbitration attracts smaller cases, a confounding factor for analysis. ${ }^{117}$

A 1981 study, perhaps the best designed of those mentioned here, used the AAA closed-claims file for southern California from 1971-1980, matched with closed claims from the NAIC census (1975-1978) from the same region. ${ }^{118}$ Again, however, relatively few arbitration claims were included (120 to 200, depending on the specific analysis), of which about forty percent went to adjudication on the merits. This imperfectly controlled comparison found that arbitration worked faster in every category of injury severity and regardless of the number of defendants, and that arbitration made payments in forty-five percent of cases compared to fifty-three percent for litigation (litigants recovered more frequently than arbitrants for comparable cases of no injury, temporary injury, and death; arbitrants more frequently for permanent injury). The study also found that arbitration indemnities were only about half the size of litigation indemnities for the temporary injuries and about five percent larger for permanent ones. ${ }^{119}$

A 1983 evaluation of early Michigan experience with arbitration compared closed claims from arbitration with those from circuit court filings during 1976-1982 for the three counties of metropolitan Detroit. ${ }^{120}$ Arbitration claim filings increased steadily for a period, then dropped, as the enabling statute came under legal attack. These legal uncertainties and the small number of cases make all results tentative; most reported differences were not major. ${ }^{121}$

proportion of claims paid ( $64 \%$ versus $66 \%$ ); and arbitration had $15 \%$ lower defense costs per closed claim.

117. Selection bias can occur because would-be claimants can choose between arbitration and conventional litigation. Under post-treatment-and-injury agreements to arbitrate, only those choosing arbitration sign up. Even under pre-treatment-and-injury agreements, courts or statutes generally allow a patient a thirty- or sixty-day grace period after treatment, during which time the agreement may be voided. See generally Ladimer, supra note 106, at 25-27, 33. Moreover, some arbitration agreements specifically include large claims. Id. at 30. Ladimer, Solomon \& Mulvihill, supra note 105 , at 462 , report that $72 \%$ of closed arbitration claims involved no injury or a temporary one, compared with $51 \%$ for litigated claims, and that permanent injury claims were similar $(25 \%$ versus $29 \%$ ), while arbitration covered far fewer deaths (3\% versus $20 \%$ ).

118. Ladimer, Solomon \& Mulvihill, supra note 105. An earlier similar examination had only 24 cases when it matched up time periods better. See Ladimer, supra note 106, at 31 .

119. Ladimer, Solomon, \& Mulvihill, supra note 105, at 462-64.

120. Applied Social Research, INC., supra note 108. The study also reports on claim files opened and closed by malpractice insurers or self insurers before any formal claim was brought to arbitration or to court.

121. The study summary reports that arbitrated cases took longer from injury to claim than litigated ones (41.1 months on average versus 39.1$)$, despite being filed faster (20.2 months versus 22.8). Applied Social Research, InC., supra note 108, at 12. Claimants were successful in $27 \%$ of all court trials and $31 \%$ of all arbitration hearings. Id. at 13 . Median payments in all closed cases were $\$ 1,000$ for arbitration and $\$ 1,875$ for court filings. Median arbitration payments exceeded courts' only for emotional/insignificant injury $(\$ 2,500$ versus $\$ 0)$ and major temporary injury $(\$ 2,250$ versus $\$ 2,000)$. Arbitration payments were far lower for significant permanent injuries and for deaths $(\$ 2,500$ versus $\$ 5,000$ and $\$ 1,000$ versus $\$ 3,875)$. Id. at 10 . The extremely low payment 
Finally, Danzon reports on a noncontrolled comparison of the claims closed by binding arbitration versus all closed claims in the 1975-1978 NAIC data (one-third of one percent closed by arbitration). ${ }^{122}$ Claimants won about as often in arbitration as in all claims (thirty-nine percent versus thirty-eight percent) and won similar amounts (about $\$ 21,000$ each); plaintiffs going to trial won far less often but much more money (fourteen percent of the time and $\$ 54,000$ ). Defense legal costs for arbitration to a decision exceeded those of preverdict settlement $(\$ 3,500$ versus $\$ 3,000)$. No separate data were available on arbitration claims settled before formal arbitration ruling.

\section{VII}

\section{Malpractice and the Health Care System}

In addition to issues regarding the basic tort litigation system for malpractice, concerns have arisen about possible spillover effects that malpractice may have on the costs of and access to health care. The most direct way that costs may be affected is that insurance premiums could lead to increases in providers' fees. Two more indirect cost effects are related to legal defense outlays and the practice of defensive medicine. Access to care might be affected by cutbacks in risky procedures, early retirements by physicians who find that they cannot pay high premiums, and refusal of certain types of patients.

\section{A. Health Care Costs}

The primary mechanism through which premiums could add to health care costs is by increasing provider fees or charges-what might be called the "pass-through" effect. Several studies have assessed the relationship between physician premiums and fees for specific procedures.123 In general, the findings suggest that higher premiums are associated with higher fees; however, the length of time for the "pass-through" to occur has not been measured. The extent of the pass-through, however, has received attention. The Greenwald and Mueller study was the only one that used a single price index to determine the impact of premiums. ${ }^{124}$ Other authors used a variety of specific fees and, consequently, produced a variety of premium effects. An analysis by Sloan concludes that the Greenwald and Mueller effect is nearly

figures for severe injuries may indicate some nonrepresentativeness in these closed claims versus those still open at the end of the study. Loss adjustment expense per closed claims averaged $\$ 3,652.50$ for arbitration, and $\$ 3,914.60$ for court cases. Id. at 12 .

The results of some small opinion surveys by written questionnaire are also reported. Generally, opinions mirror the (self-selected) respondents' interest: physicians, defendants and their attorneys, and arbitrators like the process, whereas claimants and their attorneys, as well as lawyers in general, do not. Id. at 15-25.

122. P. Danzon, supra note 2, at 202-04.

123. See, e.g., Greenwald \& Mueller, Medical Malpractice and Medical Costs in The Economics of Medical Malpractice 65 (S. Rottenberg ed. 1979); Lee \& Hadley, Physicians' Fees and Public Medical Care Programs, 16 Health Services Research 185 (1981); Sloan, Effects of Health Insurance on Physicians' Fees, 17 J. Human Resources 533 (1982).

124. Greenwald \& Mueller, supra note 123 , at 71 . 
identical to the one found in other studies. ${ }^{125}$ Based on this consensus, it appears that a doubling of premiums would result in about a ten percent increase in fees. ${ }^{126}$

Fee increases of this magnitude do not seem plausible. Since premiums represent a small share of gross practice income, a fee response of this magnitude suggests that net income could actually rise as premiums increase if the number of services provided do not fall after fees rise. In fact, analysis by Sloan revealed that net incomes do fall when premiums rise, suggesting that the total pass-through effect is well below the levels indicated by the fee responses. ${ }^{127}$ He concludes that, overall, about seventy-five percent of premium increases are recovered from patients with the remainder absorbed by the physician. ${ }^{128}$ Comparable studies of hospitals' charges and revenues do not appear to be available.

The two other cost areas mentioned above affect health expenditures in a less direct fashion. Zuckerman analyzed defendants' costs of hiring independent legal counsel (only twelve percent of physicians hire legal counsel different from that supplied by the insurer) and time lost to litigation. He concluded that neither was an extreme burden on physicians. ${ }^{129}$ The time lost, however, amounted to about $\$ 1,000$ per claim in foregone income for physicians who incurred claims between 1979 and 1983.130 Since these results are based on physician survey data, they may overstate the time associated with legal activity. Even if they do not overstate time costs and are based on a high estimate that twenty percent of physicians incur a claim per annum, litigation activities would cost the average physician less than $\$ 250$ about $0.1 \%$ of gross revenue.

Defensive medicine is the indirect cost that receives the most public attention and, if one is willing to believe any of the empirical estimates, it is potentially the most costly aspect of the entire malpractice system. Tancredi and Barondess surveyed research on defensive medicine as of 1978, and concluded that "very little solid information is available about defensive medicine." 131 Attempts to analyze the costs of defensive medicine are hindered by difficulties in identifying specific defensive procedures. The Duke Law Journal questioned doctors about treatments they would use for hypothetical cases; their responses revealed a broad variation in treatment

125. Sloan, Economic Issues in Medical Malpractice, in Fla. Medical. Ass'N, Medical Policy Guidebook 41-43 (Manue ed. 1985).

126. Id. at 42. Since average premiums represent less than five percent of average gross revenue, this effect is substantial. Assuming no volume responses, fees would need only rise by five percent to offset fully a doubling of premiums and keep incomes constant.

127. Sloan, Physician Demand for Malpractice Insurance in VANd. Inst. Pol'y STUd., ANalysis Of Data on Physician Practice Costs and Income 144-58 (1981).

128. Sloan, supra note 125 , at 43 .

129. Zuckerman, supra note 22, at 130-31.

130. Id. at 131 .

131. Tancredi \& Barondess. The Problem of Defensive Medicine, 200 Science 879, 879 (1978). Also, for an earlier, more qualitative assessment of defensive medicine, see Hershey, The Defensive Practice of Medicine-Myth or Reality, Milbank Mem. Fund Q./Health \& Soc'y, Jan. 1972, at 69. 
patterns (including defensive medicine). ${ }^{132}$ Garg, Gliebe, and Elkhatib have done what appears to be the sole retrospective study of defensive medicine based on actual medical records. This analysis of 199 patient records with 6,300 tests and $900 \mathrm{x}$-rays concluded that eight percent of the test charges and fifteen percent of the $x$-ray charges were defensive in nature. ${ }^{133}$ The size of the sample used raises serious doubts about the generalizability of its results.

Studies by Zuckerman, the American College of Obstetricians and Gynecologists (ACOG), and the California Medical Association describe aspects of defensive costs but do not estimate monetary effects. ${ }^{134}$ Zuckerman analyzes data on practice changes that, according to the physicians surveyed, were undertaken as a result of increasing malpractice premiums. Among the modifications that could increase costs, those undertaken by at least one-third of respondents were: maintaining more detailed patient records, prescribing additional tests, referring more cases, and spending more time with patients. ${ }^{135}$ There appeared to be a positive relationship between the probability of a claim and the probability of undertaking one of the actions. ${ }^{136}$ The ACOG approach to collection was similar to Zuckerman's. ACOG focused only on obstetricians, however, and found them to be more responsive to the threat of malpractice than the general physician population discussed by Zuckerman. ${ }^{137}$ This should not be surprising in light of obstetricians' above average probability of being involved in a suit.

There have been studies that attempt to attach a dollar value to the total number of defensive procedures. ${ }^{138}$ At present, the most widely cited cost estimate appears to be the one developed by the American Medical Association. Using calculations based on physician telephone surveys, the AMA concludes that twenty-five to fifty percent of the costs of physician services are the result of defensive practices, yielding an estimate of about $\$ 15.1$ billion in $1984 .^{139}$ This estimate is suspect for a number of reasons. First, the methodology used in this study is inadequately documented. Second, it seems unlikely that physicians can accurately identify, in the time allowed during a telephone survey, those procedures performed solely for defensive reasons with little or no medical benefits to the patient. Finally, the 58

132. Project, The Medical Malpractice Threat: A Study of Defensive Medicine, 1971 DukE L.J. 939, 957.

133. Garg, Gliebe \& Elkhatib, The Extent of Defensive Medicine: Some Empirical Evidence, LeGaL Aspects of Med. Prac., Feb. 1978, at 25, 29.

134. See ACOG 1985 Report, supra note 13; Hough \& Jones, Professional Liability Issues in Obstetrical Practice (pt. 2), Socioeconomic ReP., Oct./Nov. 1985, at 1; Zuckerman, supra note 22.

135. Zuckerman, supra note 22, at 131-32.

136. Id. Some studies have used premium changes as the stimulus for analyzing physicians' reactions, while others have used the threat of a suit. Increasing malpractice premiums can be thought of as a major portion of the threat of malpractice.

137. Authors' comparison between data in Zuckerman, supra note 22, at 132 , and in the ACOG 1985 REPORT, supra note 13 , table 27.

138. See, e.g., AMA TASK ForCe, Report 1, supra note 12, at 16; Tancredi \& Barondess, supra note 131.

139. AMA TASK ForCe, Report 1, supra note 12, at 16. 
implication that physician spending could be reduced by twenty-five percent without a real reduction in the quality of care seems implausible and, almost certainly, not a position supported by the AMA. Sloan aptly concludes that " $[t]$ here is a cost to defensive medicine, but it is more appropriate to list its dimensions than to place a dollar value on it." 140

\section{B. Access to Care}

The primary access issue is whether or not the number of providers available (per capita) has been reduced because of malpractice developments-premium increases, greater likelihood of claims, adverse publicity, and so on. Anecdotal evidence about early retirements is available. ${ }^{141}$ Empirical studies to date have not documented any changes in physician supply due to malpractice. Lipson found that premium increases even at the height of the mid-1970's crisis had little effect on physician practice location or supply in California. ${ }^{142}$ Sloan tentatively confirmed this finding for Florida and New York as well. ${ }^{143}$ Lipson concluded that, while general and family practitioners did restrict high-risk procedures, this did not hinder patients' access to care, except in already underserved areas. ${ }^{144}$ Although malpractice may not be reducing existing access to care, it could be slowing the growth of access to certain high-risk specialties. Unfortunately, data needed to identify this phenomenon are not available.

Even if the number of physicians is not declining, it may be that the numbers of services or patients being treated-especially in high-risk categories-are being curtailed. If this were occurring, it would be a major reason for concern. Surveys of providers clearly show that they believe this is occurring. As of 1985, twenty-three percent of obstetricians indicated that the risks of malpractice motivated them to reduce the number of high-risk pregnancies they treat. ${ }^{145}$ In fact, twelve percent of obstetricians claim to have given up obstetrics altogether. ${ }^{146}$ Data also indicated that this phenomenon is not solely confined to OBGYN's. A survey conducted by the AMA in late 1983 indicated that over one-third of physicians are now refusing certain types of cases. ${ }^{147}$ These data suggest that providers perceive that a real access problem is being created. Unless a survey of patients shows that certain types of high-risk care is becoming increasingly difficult to obtain and that this difficulty is correlated with aspects of malpractice activity, however, the provider-based resuits need to be viewed cautiously. At present, no effort

140. Sloan, supra note 125 , at 47.

141. Insurance Rates Force Doctor Out, Wash. Post, Aug. 21, 1985, at C4, col. 1; Lavin, Malpractice Pressure Drove this Doctor Out of Medicine, MED. Econ., Nov. 12, 1984, at 186.

142. A. Lipson, Medical Malpractice: The Response of Physicians to Premium Increases in California 32 (The Rand Corp., Report No. R-2026-PSEC, 1976).

143. Sloan, supra note 125 , at $43-45$.

144. A. LIPSON, supra note 142, at 32.

145. ACOG 1985 Report, supra note 13 , table 28.

146. Id.

147. Zuckerman, supra note 22, at 132. 
to explore the patient view of the access issue with respect to malpractice appears to exist.

\section{VIII}

\section{Conclusion}

Many policy disputes over medical malpractice law and insurance turn on empirical points. This article reviews quantitative information on malpractice and health policy issues; issues were excluded that were strictly related to insurance, such as the accuracy of rating and reserving methods or the effects of competition and regulation in insurance markets. As this article demonstrates, comparatively little generalizable empirical data, and even less explanation or analysis of the causes or effects of such quantitative phenomena, is available. Thus, policymakers must make decisions on malpractice reforms based on very little "hard" information. An architect of "no-fault" reform for automobile liability remarked a decade ago on the difference in knowledge about payments for motor accidents and for medical malpractice: "Empirical data in abundance have informed and enlightened legislative choices in relation to reform of the automobile accident reparation system. No such data are readily available with regard to the medical malpractice reparation system." 148 This relative lack of information remains today, despite considerable effort by a few researchers and voluminous output from interested parties.

The best documentation for liability insurance premiums and their constituent trends exists in frequency of claims and amounts of payments. Even for insurance data, however, most information is proprietary rather than public and is geographically limited rather than national in scope. Moreover, most presentations are descriptive rather than analytical and generally have been sponsored by interest groups rather than independently developed. It is certainly clear that insurance premiums have risen rapidly. Increases both in the frequency of claims and especially in the size of payments have contributed to this rise. ${ }^{149}$ The process of claims resolution is reasonably well understood in descriptive terms, although the only complete data set is from the mid-1970's. The composition of payments, their equity, and how well victims are compensated from various sources are less well known.

With regard to other factors, information is sketchier. The incidence of negligent injury is almost wholly undocumented. Very little information is patient-oriented rather than provider-or insurance-oriented. Some systematic information exists on how much of malpractice premium payments are "passed on" to patients as fee increases, but very little on how relative

148. Keeton, Compensation for Medical Accidents, in STAFf of House Comm. on InTERSTATE and Foreign Commerce, 94th Cong., 1 st Sess., An Overview of Medical Malpractice at app. 231, 244 (Comm. Print 1975).

149. Explanation for variations across states and over time are less well developed and, of course, analysis necessarily lags well behind the recent premium hikes that have prompted so much news coverage and legislative concern over the past year or two. 
premium burdens affect providers' locational decisions or patients' access to various types of care.

The impact of claims, lawsuits, and premiums on the practice of medicine and its quality remains largely a matter of anecdote and opinion. Most informed judgments support the existence of some inappropriately "defensive" medicine, but the phenomenon has proved difficult to define or measure empirically; its extent and cost remain poorly estimated. Likewise, belief that liability claims help deter bad medicine remains a reasonable conjecture, but one supported mainly by common sense, economic theory, and case histories rather than by empirical evidence.

Only four studies have analyzed already enacted legal reforms on a comparative basis, across states and over time. ${ }^{150}$ They offer only limited consistency in results, but they do agree that caps on awards seem to work as intended and that, on the whole, reform effects have not had a major impact on the system. More powerful analysis must wait for the effects of the implementation of reforms to become observable, for more comprehensive data, and possibly for a better specified analytic "model" of behavior to test against the data. Studies that offer more detail about specific alternatives, actual or proposed ("no fault," for instance), tend to be more qualitative than quantitative, and the data used tend to be specific to a particular state or site.

Quantitative analysts and scholars have thus contributed far less to malpractice debates than have interest groups and professionals applying expert opinion. The general quantitative content of argument has risen considerably since the last decade's "crisis," but most presentations remain argumentative rather than analytical.

150. Three of the studies are reviewed in this article-those by Danzon, Danzon \& Lillard, and Sloan. P. Danzon, supra note 21; P. DAnzon \& L. Lillard, supra note 70; Sloan, supra note 48; see text accompanying notes 94-103. The fourth study, also by Danzon, appears in this volume. Danzon, supra note 23 , at 57 . 
